\section{BRAZIULIAN JOURNAL}

OF MEDICAL AND BIOLOGICAL RESFARCH

www.bjournal.com.br
ISSN 0100-879X

Volume 43 (6) 522-599 June 2010

CLINICAL INVESTIGATION

Braz J Med Biol Res, J une 2010, Volume 43(6) 572-579

doi: 10.1590/S0100-879X2010007500051

Predictors of restenosis after percutaneous coronary intervention using bare-metal stents. A comparison between patients with and without dysglycemia

M.O. Lima-Filho, G.L. Figueiredo, M.C. Foss-Freitas, M.C. Foss and J.A. Marin-Neto

The Brazilian Journal of Medical and Biological Research is partially financed by

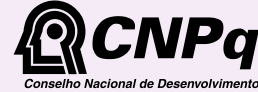

Ministério da Ciência e Tecnologia

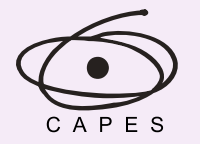

Ministério da Educação

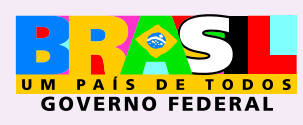

GOVERNO FEDERAL

\section{TFAPESP}

Institutional S ponsors
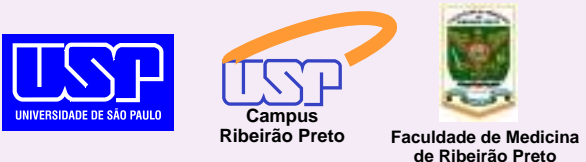

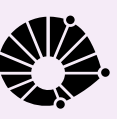

UNICAMP
Ф SHIMADZU

GE Healthcare
Hotsite of proteomics metabolomics developped by: 


\title{
Predictors of restenosis after percutaneous coronary intervention using bare-metal stents. A comparison between patients with and without dysglycemia
}

\author{
M.O. Lima-Filho ${ }^{1}$, G.L. Figueiredo ${ }^{1}$, M.C. Foss-Freitas ${ }^{2}$, \\ M.C. Foss ${ }^{2}$ and J.A. Marin-Neto ${ }^{1}$ \\ ${ }^{1}$ Divisão de Cardiologia, ${ }^{2}$ Divisão de Endocrinologia, Departamento de Clínica Médica, \\ Faculdade de Medicina de Ribeirão Preto, Universidade de São Paulo, Ribeirão Preto, SP, Brasil
}

\begin{abstract}
The objective of this study was to identify intravascular ultrasound (IVUS), angiographic and metabolic parameters related to restenosis in patients with dysglycemia. Seventy consecutive patients ( 77 lesions) selected according to inclusion and exclusion criteria were evaluated by the oral glucose tolerance test and the determination of insulinemia after a successful percutaneous coronary intervention $(\mathrm{PCl})$ with a bare-metal stent. The degree of insulin resistance was calculated by the homeostasis model assessment of insulin resistance (HOMA-IR). Six-month IVUS and angiogram follow-up were performed. Thirty-nine patients $(55.7 \%)$ had dysglycemia. The restenosis rate in the dysglycemic group was $37.2 \mathrm{vs} 23.5 \%$ in the euglycemic group $(P=0.299)$. The predictors of restenosis using bivariate analysis were reference vessel diameter (RVD): $\leq 2.93 \mathrm{~mm}(R R=0.54$; $95 \% \mathrm{Cl}=0.05-0.78 ; \mathrm{P}=0.048)$, stent area $(\mathrm{SA}):<8.91 \mathrm{~mm}^{2}(\mathrm{RR}=0.66 ; 95 \% \mathrm{Cl}=0.24-0.85 ; \mathrm{P}=0.006)$, stent volume (SV): $<119.75 \mathrm{~mm}^{3}(\mathrm{RR}=0.74 ; 95 \% \mathrm{Cl}=0.38-0.89 ; \mathrm{P}=0.0005)$, HOMA-IR: $>2.063(\mathrm{RR}=0.44 ; 95 \% \mathrm{Cl}=0.14-0.64 ; \mathrm{P}=0.027)$, and fasting plasma glucose $(F P G): \leq 108.8 \mathrm{mg} / \mathrm{dL}(\mathrm{RR}=0.53 ; 95 \% \mathrm{Cl}=0.13-0.75 ; \mathrm{P}=0.046)$. SV was an independent predictor of restenosis by multivariable analysis. Dysglycemia is a common clinical condition in patients submitted to $\mathrm{PCl}$. The degree of insulin resistance, FPG, RVD, SA, and SV were correlated with restenosis. SV was inversely correlated with an independent predictor of restenosis in patients treated with a bare-metal stent.
\end{abstract}

Key words: Coronary stents; Coronary restenosis; Insulin resistance; Diabetes mellitus; Dysglycemia

\section{Introduction}

Diabetes mellitus (DM) has been associated with poor clinical outcome and higher restenosis rate after percutaneous coronary intervention (PCI) using balloon alone, bare-metal stents (BMS) or drug-eluting stents (DES) (1-3). Although, on the basis of such evidence, DM has emerged as an independent predictor of restenosis, the mechanism responsible for this association remains to be elucidated (1-4). Several factors related to DM may be involved in the restenotic process: the duration of disease, the sustained hyperglycemic state, the requirement of insulin for control of plasma glucose concentration, the hyperinsulinemic condition of patients whose pancreatic $\beta$ cell reserve is preserved, inflammation injury, and abnormal growth factors leading to neo-intimal proliferation (5,6). Astrong correlation between pre-diabetic hyperglycemic states and increased cardiovascular risk has also been demonstrated (7). In addition, there is evidence that postprandial 2-h glycemia is better than fasting glycemia as a predictor to cardiovascular events $(8,9)$. However, the role of insulin resistance (IR) in the development of cardiovascular disease is not well defined $(10,11)$ despite the fact that IR is present in prediabetic states such as impaired glucose tolerance (IGT) or impaired fasting glycemia (IFG) (12). The role of these pre-diabetic hyperinsulinemic states in the development of restenosis after $\mathrm{PCl}$ is even less understood, although a direct correlation of neo-intimal hyperplasia after $\mathrm{PCl}$ and IR has been suggested (13-16). Therefore, the aim of the present study was to correlate glucose metabolism

Correspondence: M.O. Lima-Filho, Divisão de Cardiologia, Departamento de Clínica Médica, FMRP, USP, $14048-900$ Ribeirão Preto, SP, Brasil. Fax: +55-16-3633-0869. E-mail: I.moyses@yahoo.com or moyslima@usp.br

Received January 7, 2010. Accepted May 14, 2010. Available online June 2, 2010. Published June 11, 2010. 
parameters with intravascular ultra-sound (IVUS) and quantitative coronary angiographic (QCA) characteristics of restenosis in a population of non-selected consecutive patients undergoing $\mathrm{PCl}$ with $\mathrm{BMS}$.

\section{Material and Methods}

\section{Study population}

This was a prospective, single-center controlled cohort study designed to correlate the glycemic metabolic status of patients submitted to $\mathrm{PCl}$ using BMS with QCA and IVUS data. During a period of 18 months, from January 2001 to August 2002, we studied 76 consecutive patients selected according to strict inclusion and exclusion criteria with 84 lesions who were enrolled in this study after a successful procedure. The study was approved by the Institutional Review Board and all patients gave written informed consent after appropriate consideration of inclusion and exclusion criteria.

Procedure-related parameters such as number of stents, final pressure of deployment and type of stent were left to the discretion of the operators. All patients received combined anti-platelet therapy with acetylsalicylic acid and a thienopyridine for at least 1 month after the procedure. Glycoprotein Ilb/IIla inhibitors were not used in any patient.

Within 2 weeks after a successful $\mathrm{PCl}$ documented with QCA and IVUS, the patients were evaluated for glycemic metabolism. The patients were monitored during a 6-month follow-up period by visits at 30 days, 3 and 6 months, and coronary angiography and IVUS were repeated after this period in all but 6 patients. The data presented concern 70 patients (77 lesions) who completed the study.

\section{Inclusion and exclusion criteria}

Consecutive patients $\geq 18$ years old referred for $\mathrm{PCl}$ on the basis of having clinical and/or laboratory evidence of myocardial ischemia, with at least one coronary stenosis $\geq 70 \%$ in vessels with a reference diameter $>2.5 \mathrm{~mm}$, were considered eligible to participate in the study. The other sinequa-non criterion was to provide a signed informed consent for participating in the study protocol. The exclusion criteria were as follows: non-protected left main coronary stenosis, angiographic evidence of coronary thrombus, degenerated saphenous vein graft lesions, total occlusions, pregnancy, acute phase of a coronary syndrome.

\section{Metabolic evaluation}

The patients underwent an oral glucose tolerance test (OGTT) with assessment of glycemia and insulinemia at baseline and $2 \mathrm{~h}$ after glucose ingestion. The degree of insulin resistance was evaluated by the homeostasis model assessment method (HOMA-IR) (17).

After metabolic evaluation, 39 patients $(55.7 \%)$ with 43 lesions were found to be dysglycemic and 31 patients $(44.3 \%)$ with 34 lesions were found to be euglycemic. The dysglycemic group comprised 23 diabetic patients with 27 lesions, and 16 patients with IGT and/or IFG with 16 lesions. The OGTT was not performed in 4 diabetic patients because they were under treatment with insulin (2 patients) or with double-oral hypoglycemic drugs (2 patients).

The criterion for the diagnosis of IFG was fasting plasma glucose $(F P G) \geq 100.0 \mathrm{mg} / \mathrm{dL}(5.6 \mathrm{mM})$, but $<126 \mathrm{mg} / \mathrm{dL}(7.0$ $\mathrm{mM})$. An IGT state was characterized by FPG $<126 \mathrm{mg} /$ $\mathrm{dL}(7.0 \mathrm{mM})$ with $2-\mathrm{h}$ glycemia $\geq 140 \mathrm{mg} / \mathrm{dL}(7.8 \mathrm{mM})$ and $<200 \mathrm{mg} / \mathrm{dL}(11.1 \mathrm{mM})$. The individuals were considered to be diabetic if their FPG was $\geq 126 \mathrm{mg} / \mathrm{dL}$ and/or a $2-\mathrm{h}$ glycemia $>200 \mathrm{mg} / \mathrm{dL}$.

\section{Study endpoints}

The primary endpoint was the comparison of angiography restenosis rates between the subgroups of patients with dysglycemia and euglycemia. The secondary endpoint was the correlation of the occurrence of restenosis as determined by the binary angiographic criteria with the IVUS, QCA and metabolic parameters.

\section{Angiographic and IVUS analysis}

Patients were submitted to an angiogram and IVUS immediately and 6 months after the procedure. The QCA and IVUS analyses were performed by experienced observers who were blind to the metabolic status of the patients.

QCA was performed off-line using a previously validated (18) edge-detection system, the CAAS-II System (Pie Medical Imaging B.V., Netherlands). The analysis was performed using the standard methodology, in a frame corresponding to the diastolic phase of the cardiac cycle, in two orthogonal projections, identical at baseline, post-procedure, and at the 6-month follow-up. The following parameters were analyzed: reference vessel diameter (RVD), minimum luminal diameter, lesion length, and percent stenosis (stenosis).

The IVUS studies were performed using commercially available systems, Clear View ${ }^{\mathrm{TM}}$ or Galaxy ${ }^{\mathrm{TM}}$ (Boston Scientific, USA), and catheters with 30- or 40-MHz transducers. An automatic IVUS pullback from a position distal to the stent toward the aorto-ostial junction was performed at a speed of $0.5 \mathrm{~mm} / \mathrm{s}$, following the intracoronary administration of $200 \mu \mathrm{g}$ nitroglycerin.

The quantitative analysis of IVUS was performed according to the criteria established in the clinical expert consensus document of the American College of Cardiology, and volumetric analysis was performed using Sympson's rule (19). The following parameters were evaluated: minimum lumen area (MLA), stent area (SA) at the site of $\mathrm{MLA}\left(\mathrm{mm}^{2}\right)$, and neointimal hyperplasia area (NHA) in $\mathrm{mm}^{2}$; lumen volume, stent volume (SV), and neointimal hyperplasia volume (NHV) in $\mathrm{mm}^{3}$; and NHV/SV and NHA/ $\mathrm{SA}$ as percent. The $\mathrm{PCl}$ procedures were not guided by IVUS but were documented by IVUS, although in one case a large area of stent underexpansion was observed by IVUS, leading to an additional balloon dilation followed 
by a new and final IVUS pullback.

\section{Follow-up}

A clinical follow-up evaluation was performed 1, 3, and 6 months after the procedure. At the 6-month visit, a new angiogram with IVUS evaluation was scheduled and performed up to 2 weeks thereafter. Of the 76 patients previously enrolled, 5 refused to be submitted to another procedure and 1 patient died from a cardiovascular complication 3 months after the procedure. No further cardiovascular event was observed.

During the follow-up period, 2 patients were receiving insulin, 2 metformin plus glibenclamide, 4 only metformin, 6 only glibenclamide, and none was receiving rosiglitazone. All diabetic patients were receiving statins.

\section{Statistical analysis}

Sample size calculation. Previous studies have observed a difference in the area of neointimal hyperplasia of $64 \%$, with SD $=42$ and $95 \% \mathrm{Cl}=32-90$ in the comparison of diabetic vs non-diabetic patients and a difference of $35 \%$ with $\mathrm{SD}=28$ and $95 \% \mathrm{Cl}=7-52$ in the comparison of glucose-intolerant vs normoglycemic individuals. Based on these results, in order to detect a difference of $35 \%$ between normoglycemics and dysglycemics and of $60 \%$ between normoglycemics and diabetics, with 80 or $90 \%$ power, we would need 15 to 25 subjects per group, respectively, using a $t$-test and a two-sided level of significance.

Continuous variables are reported as means \pm SD and were analyzed for significant differences between dysglycemic and euglycemic individuals, and also between patients with and without restenosis using the Student $t$-test or the Mann-Whitney test. Categorical variables were analyzed for significant differences using the chi-square test and the Fisher exact test. Linear regression and Spearman or Pearson correlation estimates were used. One-way analysis of variance was used to determine the clinical and laboratory parameters related to a greater degree of neointimal hyperproliferation. The predictors of restenosis were evaluated by bivariate analysis, correlating the binary criteria of restenosis with the median or 75 th percentile of any continuous variable. All variables with a $P$ value $\leq 0.05$ were also evaluated by multiple logistic regression analysis. A $P$ value $\leq 0.05$ was considered to be significant.

\section{Results}

\section{Comparisons of euglycemic versus dysglycemic individuals}

There were no significant differences regarding clinical baseline characteristics between the two groups (Table 1). Lesions in the left circumflex artery were more prevalent in dysglycemic patients. No other significant difference was observed regarding the baseline angiogram characteristics, QCA parameters, or procedural results (Table 2). Similar results were observed regarding the IVUS and QCA parameters at the 6-month follow-up (Table 3).

The rate of restenosis in the dysglycemic group was $37.2 \%$ (16 of 43 lesions) versus $23.5 \%$ in the euglycemic group ( 8 of 34 lesions), but this $37 \%$ difference in restenosis was not statistically significant $(P=0.299)$.

When we subdivided the dysglycemic patient group

Table 1. Baseline clinical characteristics of the patients studied.

\begin{tabular}{lcc}
\hline & Dysglycemic & Euglycemic \\
\hline Total & $39(55.7 \%)$ & $31(44.3 \%)$ \\
BMI (means \pm SD) & $27.3 \pm 4.9$ & $25.8 \pm 3.0$ \\
Age [years (range)] & $64(47-78)$ & $61(40-85)$ \\
Male gender & $29(74.4 \%)$ & $25(80.6 \%)$ \\
Asymptomatic & $7(17.9 \%)$ & $1(3.2 \%)$ \\
Stable & $9(23.1 \%)$ & $7(22.6 \%)$ \\
ACS & $23(59.0 \%)$ & $23(74.2 \%)$ \\
Hypertension & $34(87.2 \%)$ & $23(74.2 \%)$ \\
Obesity & $13(33.3 \%)$ & $3(9.7 \%)$ \\
Dyslipidemia & $26(66.6 \%)$ & $14(45.2 \%)$ \\
Family history & $17(43.6 \%)$ & $13(41.9 \%)$ \\
Tobacco use & $13(33.3 \%)$ & $8(25.8 \%)$ \\
LVEF <0.50 & $12(30.7 \%)$ & $3(9.7 \%)$ \\
1-Vessel disease & $16(41.0 \%)$ & $16(51.6 \%)$ \\
2-Vessel disease & $17(43.6 \%)$ & $12(38.7 \%)$ \\
3-Vessel disease & $6(15.4 \%)$ & $3(9.7 \%)$ \\
\hline
\end{tabular}

Data are reported as number with percent in parentheses unless otherwise indicated. ACS = acute coronary syndrome; LVEF = left ventricle eject fraction. There were no statistically significant differences between the groups for any parameter (chi-square and Mann-Whitney tests).

Table 2. Procedural characteristics and quantitative coronary angiographic parameters.

\begin{tabular}{lcc}
\hline & Dysglycemic & Euglycemic \\
\hline LAD/RCA/LCX (\%) & $37 / 35 / 28$ & $58 / 35 / 7^{*}$ \\
Maximal inflation pressure (atm) & $15.3 \pm 2.0$ & $14.9 \pm 2.0$ \\
Stent length (mm) & $13.9 \pm 4.8$ & $12.5 \pm 3.8$ \\
RVD - baseline (mm) & $2.99 \pm 0.50$ & $2.82 \pm 0.50$ \\
MLD - baseline (mm) & $0.84 \pm 0.26$ & $0.80 \pm 0.33$ \\
Stenosis (\%) - baseline & $71.4 \pm 8.7$ & $71.3 \pm 10.5$ \\
Lesion length - baseline (mm) & $11.8 \pm 4.2$ & $11.0 \pm 3.3$ \\
RVD - post-PCI (mm) & $3.24 \pm 0.46$ & $3.09 \pm 0.39$ \\
MLD - post-PCI (mm) & $2.74 \pm 0.39$ & $2.61 \pm 0.36$ \\
Stenosis (\%) - post-PCI & $15.8 \pm 6.1$ & $15.1 \pm 6.3$ \\
\hline
\end{tabular}

Data are reported as means $\pm S D$. LAD = left anterior descendent; RCA = right coronary artery; $L C X$ = left circumflex; RVD = reference vessel diameter; $M L D=$ minimum luminal diameter; $\mathrm{PCl}=$ percutaneous coronary intervention. ${ }^{*} \mathrm{P}=0.041$ compared to dysglycemic patients (Fischer exact test and Student $t$-test). 
according to the presence of DM or IGT we observed a restenosis rate of $44.4 \%$ (12 of 27 lesions) in diabetic patients versus $25 \%$ (4 of 16 lesions) in IGT patients, a difference that was not statistically significant.

\section{Comparison of restenotic versus non-restenotic groups}

In an attempt to establish whether any metabolic, angiographic or IVUS parameter would influence the incidence of restenosis, we compared patients regarding the presence or absence of restenosis. A statistically significant difference was observed between restenotic and non-restenotic lesions in IVUS parameters correlated to vessel dimensions such as SV: $90.0 \pm 50.5$ vs $142.01 \pm 67.29 \mathrm{~mm}^{3}, \mathrm{P}$ $=0.0003$, and SA: $7.53 \pm 2.23$ vs $10.04 \pm 2.65 \mathrm{~mm}^{2}, \mathrm{P}=$ 0.0003 . Similarly, by QCA analysis, RVD was found to be significantly smaller in the group with restenosis compared to the group with non-restenotic lesions, $2.64 \pm 0.46$ vs 2.96 $\pm 0.51 \mathrm{~mm}, \mathrm{P}=0.0102$.

It is interesting to note that the MLA at follow-up correlated strongly with the SA (Figure 1). The patients with restenosis had significantly higher rates of IR as determined by HOMA-IR and more elevated values of postprandial glycemia. They also tended to have higher FPG and 2-h insulinemia (Table 4).

The predictors of coronary restenosis using bivariate analysis for the whole group were RVD: $\leq 2.93 \mathrm{~mm}$ (sample median), $\mathrm{RR}=0.54(95 \% \mathrm{Cl}=0.05-0.78), \mathrm{P}=0.048 ; \mathrm{SA}$ : $<8.91 \mathrm{~mm}^{2}$ (sample median), $\mathrm{RR}=0.66(95 \% \mathrm{Cl}=0.24-$ $0.85), \mathrm{P}=0.006$; $\mathrm{SV}$ : $<119.75 \mathrm{~mm}^{3}$ (sample median), $\mathrm{RR}=0.74(95 \% \mathrm{Cl}=0.38-0.89), \mathrm{P}=0.0005$; HOMA-IR: $>2.063$ (sample median), $\mathrm{RR}=0.44(95 \% \mathrm{Cl}=0.14-0.64)$,

Table 3. Intravascular ultrasound and quantitative coronary angiographic parameters at 6-month follow-up.

\begin{tabular}{lrc}
\hline & Dysglycemic & Euglycemic \\
\hline Lumen area $\left(\mathrm{mm}^{2}\right)$ & $4.40 \pm 2.72$ & $4.15 \pm 2.18$ \\
Stent area $\left(\mathrm{mm}^{2}\right)$ & $9.38 \pm 2.97$ & $9.06 \pm 2.54$ \\
Neointimal hyperplasia area $\left(\mathrm{mm}^{2}\right)$ & $4.98 \pm 1.94$ & $4.90 \pm 1.45$ \\
NHA/SA $\%)$ & $55.4 \pm 16.8$ & $56.0 \pm 14.6$ \\
Lumen volume $\left(\mathrm{mm}^{3}\right)$ & $87.8 \pm 61.3$ & $67.5 \pm 38.9$ \\
Stent volume $\left(\mathrm{mm}^{3}\right)$ & $137.3 \pm 76.3$ & $110.2 \pm 48.9$ \\
Neointimal hyperplasia volume $\left(\mathrm{mm}^{3}\right)$ & $49.5 \pm 28.3$ & $42.7 \pm 21.0$ \\
NHV/SV $(\%)$ & $39.5 \pm 18.1$ & $41.1 \pm 15.7$ \\
Reference vessel diameter $(\mathrm{mm})$ & $2.95 \pm 0.58$ & $2.75 \pm 0.40$ \\
Minimum luminal diameter $(\mathrm{mm})$ & $1.71 \pm 0.77$ & $1.71 \pm 0.62$ \\
Stenosis $(\%)$ & $44.1 \pm 19.6$ & $38.7 \pm 19.2$ \\
Late loss & $0.91 \pm 0.63$ & $1.04 \pm 0.65$ \\
\hline
\end{tabular}

Data are reported as means $\pm \mathrm{SD}$. NHA/SA = neointimal hyperplasia area/stent area; NHV/SV = neointimal hyperplasia volume/ stent volume. There were no statistically significant differences between the groups for any parameter (Student $t$-test)
$\mathrm{P}=0.027$, and FPG: $\leq 108.8 \mathrm{mg} / \mathrm{dL}$ (sample median), RR $=0.53(95 \% \mathrm{Cl}=0.13-0.75), \mathrm{P}=0.046$ (Table 5). Only SV remained as independent predictor of restenosis by the multiple linear regression analysis (Table 6).

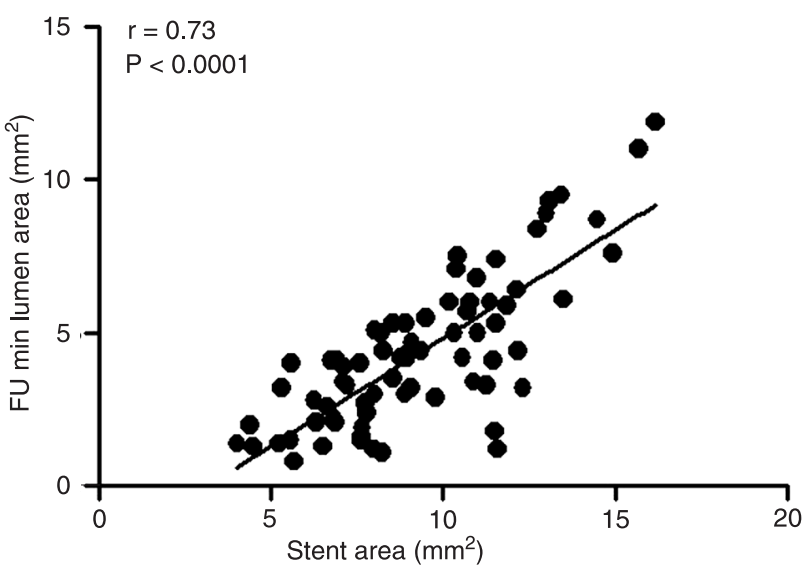

Figure 1. Relation between minimum lumen area and stent area measured by intravascular ultrasound at 6 months of follow-up (FU).

Table 4. Comparison of the metabolic parameters of the groups with and without restenosis.

\begin{tabular}{lcc}
\hline & Restenosis & No restenosis \\
\hline HOMA-IR & $3.7 \pm 3.0$ & $2.9 \pm 3.4^{*}$ \\
Insulin $(\mu \mathrm{U} / \mathrm{mL})$, fasting & $11.5 \pm 6.0$ & $10.4 \pm 8.2$ \\
Glycemia $(\mathrm{mg} / \mathrm{dL})$, fasting & $125.7 \pm 66.1$ & $98.0 \pm 31.0$ \\
Insulin $(\mu \mathrm{U} / \mathrm{mL}), 120 \mathrm{~min}$ & $110.8 \pm 71.2$ & $83.3 \pm 63.9$ \\
Glycemia $(\mathrm{mg} / \mathrm{dL}), 120 \mathrm{~min}$ & $184.8 \pm 90.2$ & $147.2 \pm 72.2^{*}$ \\
\hline
\end{tabular}

Data are reported as means $\pm \mathrm{SD}$. HOMA-IR $=$ homeostasis model assessment of insulin resistance. ${ }^{*} \mathrm{P}<0.05$ compared to restenosis (Student $t$-test).

Table 5. Predictors of restenosis - bivariate analysis.

\begin{tabular}{lcl}
\hline & Relative risk & P \\
\hline Fasting glycemia $<108.0 \mathrm{mg} / \mathrm{dL}^{\mathrm{a}}$ & $0.53(0.13-0.75)$ & 0.046 \\
Glycemia $-120 \mathrm{~min}<183.5 \mathrm{mg} / \mathrm{dL}^{\mathrm{a}}$ & $0.45(0.04-0.71)$ & 0.093 \\
Fasting insulin $<13.0 \mu \mathrm{U} / \mathrm{mL}^{\mathrm{a}}$ & $0.28(0.41-0.63)$ & 0.679 \\
Insulin - $120 \mathrm{~min} \geq 78.0 \mu \mathrm{U} / \mathrm{mL}^{\mathrm{b}}$ & $0.45(0.04-0.71)$ & 0.093 \\
HOMA-IR $<2.06^{\mathrm{a}}$ & $0.44(0.14-0.64)$ & 0.027 \\
RVD $\geq 2.82 \mathrm{~mm}^{\mathrm{a}}$ & $0.60(0.15-0.81)$ & 0.014 \\
Stent volume $\geq 119.8 \mathrm{~mm}^{3 a}$ & $0.74(0.38-0.89)$ & 0.0005 \\
Stent area $\geq 8.91 \mathrm{~mm}^{2 \mathrm{a}}$ & $0.66(0.24-0.85)$ & 0.006 \\
\hline
\end{tabular}

HOMA-IR = homeostasis model assessment of insulin resis-

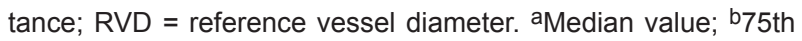
percentile value. 
Table 6. Predictors of restenosis - multiple logistic regression analysis.

\begin{tabular}{lccccc}
\hline & Beta coefficient & Standard error & Wald coeff./SE & Prob & Exp (beta) \\
\hline HOMA-IR & 2.71675 & 1.70828 & 1.59034 & 0.11 & 15.13 \\
Fasting glycemia & -2.1871 & 1.78436 & -1.22571 & 0.22 & 0.1122 \\
Stent volume & 4.34938 & 1.76364 & 2.46615 & 0.013 & 77.43 \\
Stent area & 2.19828 & 1.87928 & 1.16975 & 0.24 & 9.01 \\
RVD & -0.85389 & 1.6749 & -0.05982 & 0.96 & 0.9182 \\
Constant & -5.07521 & 2.4083 & -2.10738 & 0.017 & - \\
\hline
\end{tabular}

HOMA-IR = homeostasis model assessment of insulin resistance; RVD = reference vessel diameter.

\section{Discussion}

Although DM, IGT and IFG are associated with increased cardiovascular risk, the assessment of glucose metabolism is commonly neglected in many patients treated with $\mathrm{PCl}$ $(8,9)$. In a cohort of 1612 patients, $61 \%$ of them were found to have diabetes or pre-diabetes (20). Similarly, the present study showed that $55.7 \%$ of consecutive patients being treated with $\mathrm{PCl}$ had dysglycemia. However, our investigation differs from that seminal study by the fact that we performed an OGTT and the criterion for IFG was updated according to the last ADA Expert Document Consensus (FPG $\geq 100 \mathrm{mg} / \mathrm{dL}$ ) (21). The stricter criterion for defining patients with IFG used in our study was justified by the fact that, although a tighter glycemic control has been shown to be effective in the prevention of microvascular disease in diabetic and pre-diabetic patients, no similar clear relation has been established regarding the development of macrovascular atherosclerotic complications in this set of patients (22).

A correlation between glycated hemoglobin ( $\mathrm{HbA} 1 \mathrm{c})$ levels and major adverse cardiac events after $\mathrm{PCl}$ has been shown in non-diabetic patients (23). However, in the cited study the patients were only considered diabetic if previously diagnosed or if they had $\mathrm{HbA} 1 \mathrm{c}>7.0 \%$, a criterion not consistent with current standards (21). The same group of investigators also found a relationship between glycemic control and rate of restenosis, considering a level of $\mathrm{HbA} 1 \mathrm{c}>7.0 \%$ as a parameter of uncontrolled DM (24). This observation was not confirmed by two recent studies that did not show a direct relationship between target lesion revascularization and other cardiac events after $\mathrm{PCl}$ and $\mathrm{HbA} 1 \mathrm{c}$ levels $(25,26)$. The present study, in which we actively established the diagnosis of both DM and pre-diabetes status using currently accepted methodology $(21,27)$, confirms and extends the results of these previous studies. Thus, by bivariate analysis, we observed a reduction in the risk of restenosis as defined by the binary criteria, when FPG $\leq 108 \mathrm{mg} / \mathrm{dL}$ (median), $\mathrm{RR}=0.53(95 \% \mathrm{Cl}=0.13-0.75), \mathrm{P}$ $=0.046$. These results are similar to those of Muhlestein et al. (20) who found a 3-fold increase in the risk of death during a follow-up of $2.8 \pm 1.2$ years after $\mathrm{PCl}$ when $\mathrm{FPG}$ exceeded $109 \mathrm{mg} / \mathrm{dL}$.

In dysglycemic patients with either microvascular or macrovascular disease, the postprandial glycemia has been considered a better predictor of mortality than FPG $(8,9)$. In our study, we observed a trend to a reduction of restenosis rate when the 120 -min glycemia was $<183.5 \mathrm{mg} / \mathrm{dL}$.

No direct or independent relation of IR to coronary artery disease has been established $(10,11,28,29)$. Moreover, the relation of IR to restenosis is even more elusive because the few studies addressing this issue used different methodology, and the results were highly heterogeneous $(13-16,30,31)$. For instance, an unexpected inverse relationship between insulinemia levels and restenosis rate was described following excimer laser coronary angioplasty (30). Since fasting hyperinsulinemia is an unquestionable parameter of IR (32), there is no logical explanation for this finding. In our study, no differences in fasting insulinemia levels were found between the restenotic and non-restenotic groups; only a trend toward higher 120-min insulinemia levels was observed in the restenotic group. In the bivariate analysis, we observed that the degree of $\mathrm{IR}$, as defined by an HOMA-IR <2.06, decreased the risk of restenosis, but multivariable analysis did not show an independent relationship between these variables. Our results agree with published data describing a relationship between greater neointimal index area (not measured with IVUS as in our study) and IR (16). Other studies also described a relationship between restenosis and IR, but in most of them diabetic patients were excluded and no IVUS measurements were performed $(13,15,31)$. In the only published study in which diabetic patients were included and a direct relationship between plasma insulin levels and restenosis was described, IVUS was not used, and, unexpectedly, QCA parameters related to vessel diameter were not considered to be predictors of restenosis (14). In our study, as in previous trials, RVD was a significant predictor of restenosis $(4,33)$. We also observed that SA measured by IVUS was significantly and inversely related to the rate of restenosis. A minimal 
stent area $>6.5 \mathrm{~mm}^{2}$ determined by IVUS right after the procedure has been previously described to be associated with nearly $95 \%$ freedom from subsequent new target lesion revascularization at 9-month follow-up (34). The same group of investigators emphasized the importance of stent expansion through a sub-study of DES in the SIRIUS trial (35). The present findings fully agree with these data - the regression coefficient we observed lies exactly in the middle between the DES and BMS groups analyzed in the SIRIUS sub-study, but the cut-off points of minimal stent area were different, 8.91 vs $6.5 \mathrm{~mm}^{2}$ as predictors of restenosis. This might be partially explained by the fact that we considered the binary angiographic definition of restenosis, and those studies considered the need of new target lesion revascularization (34) and an MLA $<4.0 \mathrm{~mm}^{2}$ by IVUS follow-up (35) for the definition of restenosis.

The present study is the first to show that SV is an independent predictor of restenosis. IVUS parameters as predictors of restenosis were previously described in study with Palmaz-Schatz stents (36). In another study, a chart based on IVUS data from five trials was constructed, and by bivariate analysis SV was not considered to be a predictor of restenosis. Interestingly, by multivariable logistic regression analysis with multiple models containing two IVUS parameters, the SV associated with stent length were considered to be predictors of restenosis (37). It is important to point out that in our study there was no significant difference between the groups with and without restenosis regarding stent length.

Among other characteristics, our study differs from the previous investigations in that we prospectively included consecutive patients, used eight different stent types, and eventually had more than $50 \%$ of our patients being at higher risk of restenosis based on their dysglycemic status.

Lesion length was similar in both groups, and the reference vessel diameter of dysglycemics was higher than that of the euglycemic group (without statistical significance). Since more than one third of dysglycemic patients were diabetics, these are unexpected findings, since diabetes mellitus is generally associated with longer lesions and smaller vessels. We do not have an explanation for this observation. But the same finding has been reported in most studies showing no difference in terms of vessel diameter when comparing diabetics and non-diabetics. Maybe this merely reflects screening bias since usually diabetic patients with small vessels and long lesions are not referred for $\mathrm{PCl}$.

Recently, a meta-analysis showed a direct relationship between C-reactive protein and angiographic restenosis after bare-metal stent implantation (38). Also, a recent study (39) showed that both diabetic and non-diabetic patients exhibited an inflammatory response after $\mathrm{PCl}$, expressed by C-reactive protein levels, and that the intensity of this reaction was more pronounced in diabetic patients. However, we have no data on inflammatory markers from our investigation.

Finally, although in some countries the mainstay of $\mathrm{PCl}$ currently lies in the use of DES for diabetic patients, this is not the case in our country, mainly because of economic limitations. Moreover, a recent study using data from the National Heart, Lung and Blood Institute of Health showed that, in comparison to BMS, the use of DES had a positive impact on cardiac events in diabetic patients not receiving insulin, but not on those under insulin treatment (40). Hence, the present data are pertinent for the great majority of dysglycemic patients treated with bare-metal stents in this and other developing countries.

\section{Clinical implications}

With current difficulties for a more widespread use of DES, the concept that larger reference and luminal diameters may protect against the physiological consequences of neointimal hyperplasia is still valid, even in patients at higher risk of restenosis because of a dysglycemic status. Although the biologic variability of neointimal hyperplasia in the BMS restenosis process is influenced by metabolic status, its clinical impact mostly depends on procedural and anatomical factors. The same amount of neointimal hyperplasia may produce different clinical outcomes, basically depending on the vessel and stent diameters. Larger studies are necessary using new available technologies such as last generation DES in association with optimal medical therapy to resolve this issue.

\section{Study limitations}

This was a single-center study with a small sample. The metabolic parameters were evaluated only at baseline and did not include measurement of $\mathrm{HbA} 1 \mathrm{c}$ or anti-inflammatory markers such as C-reactive protein levels. Hence, no information was obtained on how the glycemic status, a factor potentially influencing the restenosis process, was maintained during follow-up. In theory, the metabolic status of the patients could also have changed between the procedure and the time of the evaluation. However, the metabolic status of the patients was assessed within 2 weeks following the index procedure. In fact, most patients were evaluated metabolically within the first week. Hence, we would not expect to observe a dramatic change in glycemic metabolism within such a short period of time. Neither would we assume that the procedure itself could change the metabolic status of the patients, since there is not one single study showing a dysglycemic condition triggered by a cardiovascular event or percutaneous coronary intervention. Because we included patients with DM, the trend toward more restenosis among the patients with dysglycemia could have been driven by this well-known predictor. However, the fact that by bivariate analysis the fasting glycemia level correlated with the appearance of restenosis, supports the conclusion that less advanced dysglycemia conditions are indeed associated with this complication of PCl. Finally, 
the IR was not evaluated using the gold-standard method, the hyperinsulinemic-euglycemic clamp technique, but this limitation probably would not have influenced the results of the study.

We conclude that dysglycemia is a common clinical condition in patients submitted to $\mathrm{PCl}$. After $\mathrm{PCl}$ using BMS, coronary restenosis tended to be more frequent in patients with dysglycemia compared to euglycemic patients. The degree of IR and the FPG levels correlated with the

\section{References}

1. Carrozza JP Jr, Kuntz RE, Fishman RF, Baim DS. Restenosis after arterial injury caused by coronary stenting in patients with diabetes mellitus. Ann Intern Med 1993; 118: 344-349.

2. Abizaid A, Kornowski R, Mintz GS, Hong MK, Abizaid AS, Mehran $R$, et al. The influence of diabetes mellitus on acute and late clinical outcomes following coronary stent implantation. J Am Coll Cardiol 1998; 32: 584-589.

3. Elezi S, Kastrati A, Pache J, Wehinger A, Hadamitzky M, Dirschinger J, et al. Diabetes mellitus and the clinical and angiographic outcome after coronary stent placement. J Am Coll Cardiol 1998; 32: 1866-1873.

4. Cutlip DE, Chauhan MS, Baim DS, Ho KK, Popma JJ, Carrozza JP, et al. Clinical restenosis after coronary stenting: perspectives from multicenter clinical trials. J Am Coll Cardiol 2002; 40: 2082-2089.

5. Kornowski R, Mintz GS, Kent KM, Pichard AD, Satler LF, Bucher TA, et al. Increased restenosis in diabetes mellitus after coronary interventions is due to exaggerated intimal hyperplasia. A serial intravascular ultrasound study. Circulation 1997; 95: 1366-1369.

6. Aronson D, Bloomgarden Z, Rayfield EJ. Potential mechanisms promoting restenosis in diabetic patients. $J$ Am Coll Cardiol 1996; 27: 528-535.

7. Levitan EB, Song Y, Ford ES, Liu S. Is nondiabetic hyperglycemia a risk factor for cardiovascular disease? A metaanalysis of prospective studies. Arch Intern Med 2004; 164: 2147-2155.

8. Qiao Q, Pyorala K, Pyorala M, Nissinen A, Lindstrom J, Tilvis $\mathrm{R}$, et al. Two-hour glucose is a better risk predictor for incident coronary heart disease and cardiovascular mortality than fasting glucose. Eur Heart J 2002; 23: 1267-1275.

9. Glucose tolerance and cardiovascular mortality: comparison of fasting and 2-hour diagnostic criteria. Arch Intern Med 2001; 161: 397-405.

10. Ruige JB, Assendelft WJ, Dekker JM, Kostense PJ, Heine RJ, Bouter LM. Insulin and risk of cardiovascular disease: a meta-analysis. Circulation 1998; 97: 996-1001.

11. Despres JP, Lamarche B, Mauriege P, Cantin B, Dagenais GR, Moorjani S, et al. Hyperinsulinemia as an independent risk factor for ischemic heart disease. N Engl J Med 1996; 334: 952-957.

12. Reaven GM. Banting lecture 1988. Role of insulin resistance in human disease. Diabetes 1988; 37: 1595-1607.

13. Nishimoto $Y$, Miyazaki $Y$, Toki $Y$, Murakami R, Shinoda M, Fukushima A, et al. Enhanced secretion of insulin plays a role in the development of atherosclerosis and restenosis of coronary arteries: elective percutaneous transluminal restenosis rate, but were not considered to be independent predictors of this complication. The stent dimensions, measured by both IVUS and QCA, were inverse determinants of restenosis rates. SV by IVUS was independently related to restenosis.

\section{Acknowledgments}

\author{
Research supported by FAPESP (\#99/07143-2).
}

coronary angioplasty in patients with effort angina. J Am Coll Cardiol 1998; 32: 1624-1629.

14. Nishio K, Fukui T, Tsunoda F, Kawamura K, Itoh S, Konno $\mathrm{N}$, et al. Insulin resistance as a predictor for restenosis after coronary stenting. Int J Cardiol 2005; 103: 128-134.

15. Sekiguchi $M$, Kurabayashi $M$, Adachi $H$, Hoshizaki $H$, Oshima S, Taniguchi K. Usefulness of insulin resistance measured by homeostasis model assessment in predicting restenosis after coronary stent placement in nondiabetic patients. Am J Cardiol 2004; 93: 920-922.

16. Takagi T, Yoshida K, Akasaka T, Kaji S, Kawamoto T, Honda $Y$, et al. Hyperinsulinemia during oral glucose tolerance test is associated with increased neointimal tissue proliferation after coronary stent implantation in nondiabetic patients: a serial intravascular ultrasound study. J Am Coll Cardiol 2000; 36: 731-738

17. Matthews DR, Hosker JP, Rudenski AS, Naylor BA, Treacher DF, Turner RC. Homeostasis model assessment: insulin resistance and beta-cell function from fasting plasma glucose and insulin concentrations in man. Diabetologia 1985; 28 : 412-419.

18. Reiber JH, Koning G, Goedhart B. The effect of DICOM on QCA and clinical trials. Int J Card Imaging 1998; 14 (Suppl 1): 7-12.

19. Mintz GS, Nissen SE, Anderson WD, Bailey SR, Erbel R, Fitzgerald PJ, et al. American College of Cardiology Clinical Expert Consensus Document on Standards for Acquisition, Measurement and Reporting of Intravascular Ultrasound Studies (IVUS). A report of the American College of Cardiology Task Force on Clinical Expert Consensus Documents. J Am Coll Cardiol 2001; 37: 1478-1492.

20. Muhlestein JB, Anderson JL, Horne BD, Lavasani F, len Maycock CA, Bair TL, et al. Effect of fasting glucose levels on mortality rate in patients with and without diabetes mellitus and coronary artery disease undergoing percutaneous coronary intervention. Am Heart J 2003; 146: 351-358.

21. Genuth S, Alberti KG, Bennett P, Buse J, Defronzo R, Kahn $\mathrm{R}$, et al. Follow-up report on the diagnosis of diabetes mellitus. Diabetes Care 2003; 26: 3160-3167.

22. Intensive blood-glucose control with sulphonylureas or insulin compared with conventional treatment and risk of complications in patients with type 2 diabetes (UKPDS 33). UK Prospective Diabetes Study (UKPDS) Group. Lancet 1998; 352: 837-853

23. Corpus RA, O'Neill WW, Dixon SR, Timmis GC, Devlin WH. Relation of hemoglobin $\mathrm{A} 1 \mathrm{c}$ to rate of major adverse cardiac events in nondiabetic patients undergoing percutaneous 
coronary revascularization. Am J Cardiol 2003; 92: 12821286.

24. Corpus RA, George PB, House JA, Dixon SR, Ajluni SC, Devlin $\mathrm{WH}$, et al. Optimal glycemic control is associated with a lower rate of target vessel revascularization in treated type II diabetic patients undergoing elective percutaneous coronary intervention. J Am Coll Cardiol 2004; 43: 8-14.

25. Kauffman AB, Delate T, Olson KL, Cymbala AA, Hutka KA, Kasten SL, et al. Relationship between haemoglobin A1C values and recurrent cardiac events: A retrospective, longitudinal cohort study. Clin Drug Investig 2008; 28: 501-507.

26. Lemesle G, Bonello L, de Labriolle A, Maluenda G, Syed AI, Collins SD, et al. Prognostic value of hemoglobin A1C levels in patients with diabetes mellitus undergoing percutaneous coronary intervention with stent implantation. Am J Cardiol 2009; 104: 41-45.

27. World Health Organization. Definition, diagnosis and classification of diabetes mellitus and its complications: part 1: report of a WHO consultation: diagnosis and classification of diabetes mellitus. Geneva: World Health Organization; 1999.

28. Gaudet D, Vohl MC, Perron P, Tremblay G, Gagne C, Lesiege $D$, et al. Relationships of abdominal obesity and hyperinsulinemia to angiographically assessed coronary artery disease in men with known mutations in the LDL receptor gene. Circulation 1998; 97: 871-877.

29. Reaven GM, Chen YD. Insulin resistance, its consequences, and coronary heart disease. Must we choose one culprit? Circulation 1996; 93: 1780-1783.

30. Rabbani LE, Edelman ER, Ganz P, Selwyn AP, Loscalzo $\mathrm{J}$, Bittl JA. Relation of restenosis after excimer laser angioplasty to fasting insulin levels. Am J Cardiol 1994; 73: 323-327.

31. Radke PW, Voswinkel M, Reith M, Kaiser A, Haager PK, Hanrath $P$, et al. Relation of fasting insulin plasma levels to restenosis after elective coronary stent implantation in patients without diabetes mellitus. Am J Cardiol 2004; 93: 639-641.

32. Kim SH, Reaven GM. Insulin resistance and hyperinsulinemia: you can't have one without the other. Diabetes Care
2008; 31: 1433-1438.

33. Suselbeck T, Latsch A, Siri H, Gonska B, Poerner T, Pfleger $\mathrm{S}$, et al. Role of vessel size as a predictor for the occurrence of in-stent restenosis in patients with diabetes mellitus. Am J Cardiol 2001; 88: 243-247.

34. Morino Y, Honda Y, Okura H, Oshima A, Hayase M, Bonneau $\mathrm{HN}$, et al. An optimal diagnostic threshold for minimal stent area to predict target lesion revascularization following stent implantation in native coronary lesions. Am J Cardiol 2001; 88: 301-303.

35. Sonoda S, Morino Y, Ako J, Terashima M, Hassan AH, Bonneau $\mathrm{HN}$, et al. Impact of final stent dimensions on long-term results following sirolimus-eluting stent implantation: serial intravascular ultrasound analysis from the SIRIUS trial. J Am Coll Cardiol 2004; 43: 1959-1963.

36. Hoffmann R, Mintz GS, Mehran R, Pichard AD, Kent KM, Satler LF, et al. Intravascular ultrasound predictors of angiographic restenosis in lesions treated with Palmaz-Schatz stents. J Am Coll Cardiol 1998; 31: 43-49.

37. de Feyter PJ, Kay P, Disco C, Serruys PW. Reference chart derived from post-stent-implantation intravascular ultrasound predictors of 6-month expected restenosis on quantitative coronary angiography. Circulation 1999; 100: 1777-1783.

38. Ferrante G, Niccoli G, Biasucci LM, Liuzzo G, Burzotta F, Galiuto L, et al. Association between C-reactive protein and angiographic restenosis after bare metal stents: an updated and comprehensive meta-analysis of 2747 patients. Cardiovasc Revasc Med 2008; 9: 156-165.

39. Paiva MS, Serrano CV Jr, Nicolau JC, Jalbut BO, Fernandes $\mathrm{JL}$, De Lemos JA, et al. Differences in the inflammatory response between patients with and those without diabetes mellitus after coronary stenting. J Interv Cardiol 2008; 21 : 403-409.

40. Mulukutla SR, Vlachos HA, Marroquin OC, Selzer F, Holper EM, Abbott JD, et al. Impact of drug-eluting stents among insulin-treated diabetic patients: a report from the National Heart, Lung, and Blood Institute Dynamic Registry. JACC Cardiovasc Interv 2008; 1: 139-147. 